\title{
A ARBITRAGEM E O DIREITO DO CONSUMIDOR
}

\author{
Antonio Junqueira de Azevedo \\ Professor Titular de Direito Civil da USP \\ Ex-Diretor da Faculdade de Direito da USP
}

\begin{abstract}
Resumo:
Este artigo visa resolver o aparente conflito entre a Lei de Arbitragem (Lei n. 9.307, de 1996) que permite a cláusula compromissória nos contratos de adesão e o Código de Defesa do Consumidor (Lei n. 8.078, de 1990) que, em seu art. 51, VII, considera a mesma cláusula como abusiva. Para melhor solução da questão, o artigo procura fixar cada uma dessas leis na sua circunstância específica, defendendo a idéia de que, hoje, está a se viver a $4^{\mathrm{a}}$ fase do direito moderno, caracterizada pela complexidade, - o que implica manutenção das fases anteriores, e não, substituição de uma por outra. Seguese daí, que ambas as leis estão vigentes, aplicando-se cada uma no seu próprio campo.
\end{abstract}

\begin{abstract}
:
The purpose of this article is to solve the apparent conflict between the Arbitration Law (Lei de Arbitragem Lei n. 9.307/96) that allows the arbitration clause in the standard contracts and the Consumer's Rights Code (Código de Defesa do Consumidor Lei n. 8.078/90) that considers abusive such clause in its art. 51, VII. For better understanding of the question, this article tries to establish each law under its specific circunstance, defending the idea we are in the 4th phase of the modern law, characterized by complexity wich implies maintenance of the former phases instead of substituing one by another. Therefore, it can be infered that both laws are in force, each one in its own field.
\end{abstract}

Unitermos: Lei de Arbitragem. Código de Defesa do Consumidor.

I - A Lei de Arbitragem, o Código de Defesa do Consumidor e suas respectivas circunstâncias.

Desde o início do século XIX até hoje, o direito romano-germânico passou por quatro fases: a civilista, a de "comercialização". a de publicização e, agora, a de um direito pluralista e complexo.

$\mathrm{Na}$ primeira metade do século passado, graças especialmente ao liberalismo político e ao movimento geral de codificação, de que o Código Civil 
francês (1804) foi o modelo, o Direito Civil deu o tom a todo o sistema jurídico. A partir da segunda metade do século XIX, porém, por força da exacerbação da visão "burguesa" da vida, com a lei se tornando praticamente sinônimo de "direito" e o Estado se amoldando ao liberalismo econômico, a linha diretriz do mundo jurídico foi a de segurança dos negócios; daí, falar-se em "comercialização" do direito (cf. Galgano, 1980, pp. 28 e ss., com referência a Ripert e Pasukanis). Essa preocupação, aliás, se revela claramente em dois Códigos Civis importantes, ainda vigentes, ambos do final do período: o BGB (publicado em 1896) e o próprio Código Civil brasileiro (publicado em 1916, mas feito com base em Anteprojeto de 1899). A $3^{\text {a }}$ fase, já própria deste século, é a de publicização do direito, com o Estado interventor, atribuindo-se ao ordenamento jurídico não apenas a função de organizar a vida social e solucionar conflitos mas também a de distribuir renda, protegendo os que têm menos condições de negociação, e, especialmente, a de promover a economia. Hoje, diante do grande fracasso da economia comunista na antiga União Soviética e países satélites, abalaram-se as convicções de políticos e juristas, sobre o direito e o Estado; estamos na $4^{\mathrm{a}}$ fase e as concepções dominantes trazem a tônica da redução do Estado. Fala-se muito em "crise" (do direito e do Estado), ao mesmo tempo que se acentuam, no discurso, aspectos como a globalização da economia e as modificações tecnológicas, inclusive na organização das empresas, com a produção dispersa em unidades, formando "redes", e não mais concentrada nas grandes linhas de montagem, da fase anterior.

Ora, é com o pano-de-fundo desse quadro atual, dito de "pósmodernidade", que deve ser entendida a Lei de Arbitragem (Lei n. 9.307, de 1996). Ela revela, antes de mais nada, a mudança de mentalidade: do Estado-Demiurgo, ao Estado diminuído nas suas funções. No que nos importa, vê-se logo que a finalidade, ou a teleologia, da nova Lei é a de que uma parte do que era atribuído ao EstadoPoder Judiciário passe a ser resolvido fora de sua estrutura. Por força dessa diminuição, se crise existe, é ela, do Estado e do direito público (direito processual, ou, como se dizia antigamente, "direito judiciário") mas não, do direito privado que, pelo contrário, com a arbitragem, vê aumentado seu campo de atuação.

Como quer que seja, há, sobre arbitragem, um conflito de "filosofia" entre duas leis vigentes: a do Código de Defesa do Consumidor, que é lei protetiva, própria do Estado atuante e cujo art. 51, inciso VII, prevê como abusivas as cláusulas que "determinam a utilização compulsória da arbitragem" e a da Lei de Arbitragem, própria do Estado reduzido, cujo art. $3^{\circ}$ faculta às partes interessadas 
dispensar o Judiciário e submeter seus litígios a juízo arbitral, mediante convenção de arbitragem. Uma lei proíbe o que a outra favorece. Apressemo-nos, porém, a afirmar que o conflito de "filosofia" entre duas leis não-significa fatalmente conflito de regras, mesmo porque o ordenamento, como é sabido, tem disposições para eliminar esses conflitos (art. $2^{\circ}$, da Lei de Introdução ao Código Civil). Entretanto, a indicação do conflito dos princípios inspiradores de uma e outra lei importa por duas razões: primeiro, porque demonstra $a b$ initio a ilusão de se procurar uma harmonia intrínseca no ordenamento jurídico, como se algum legislador mítico, isento de contradições, fosse o autor de todas as leis; e, em segundo lugar, porque, sendo leis que obedecem a orientações diferentes, estamos diante de unidades normativas, cuja coerência interna deve ser respeitada, mas que põem ao intérprete a necessidade de realizar sua compatibilização externa. Em termos de hermenêutica: é ilusória a chamada interpretação sistemática global — um critério a abandonar (Lipari, 1986) - mas há que se respeitar a interpretação lógico-sistemática de cada unidade normativa e compatibilizá-las entre si, conforme a Constituição.

Diga-se, entre parêntesis, que muitos juristas chamariam a essas unidades normativas de "microssistemas", expressão atraente, que exigiria, porém, a nosso ver, para ser aplicada, algo mais que a simples unidade normativa; deveria haver, também, órgãos de recepção, ou de input, e de emissão, ou de output, que, de fato, talvez existam no direito do consumidor, - com consumidores e operadores do direito atuando na primeira função e instituições, como os Procons e as varas especializadas, na segunda — , mas que, por ora, ainda não se vêem na arbitragem.

$\mathrm{O}$ ordenamento jurídico está organizado em diferentes "camadas" de leis. No caso brasileiro, se o Código Civil é da fase da "comercialização", ou da preocupação com a segurança dos negócios, - e, nesse sentido, não previu a lesão nem a revisão judicial dos contratos, em casos de não-equivalência econômica entre prestação e contraprestação; foi anticausalista e chegou até mesmo a trazer capítulo sobre os títulos ao portador; estabeleceu a mora ex re; etc. etc.-, já o Código de Defesa do Consumidor, protetivo até no nome, previu a lesão e a revisão judicial $\left(\right.$ art. $\left.6^{\circ}, \mathrm{V}\right)$, trouxe a regra da boa-fé objetiva (arts. $4^{\circ}$, III e $\left.51, \mathrm{VV}\right)$, possibilitou, em certas circunstâncias, para o consumidor, o arrependimento do contrato (art. 49) e, inversamente, para o fornecedor, tornou vinculante qualquer oferta e até mesmo a publicidade, desde que suficientemente precisa (art. 35, I). Por aí, percebe-se que o Código Civil dá tratamento igual às situações, especialmente negociais, mantendo desiguais as pessoas, enquanto, o Código de Defesa do Consumidor, no extremo 
oposto, desiguala o tratamento das situações, para dar igualdade às pessoas ("equal treatment" versus "treatment as an equal" - Dworkin, 1991). Ambos vigentes, vêem, agora, a eles se acrescentar a Lei de Arbitragem, própria de nova visão do direito e do Estado, tudo demonstrando a superposição de "camadas", dentro da grande complexidade do direito atual.

Do exposto, percebe-se que, se uma fase histórica sucede à outra, o mesmo não acontece - e é isto que importa salientar - com o direito e as instituições. Nesse ponto, o paralelismo a ser feito é com a biologia; na evolução dos seres vivos, o antigo não é substituído pelo novo; o antigo persiste e ambos, antigo e novo, coexistem; a bactéria, um dos mais antigos seres vivos, convive com o homem, um dos mais novos. A evolução, na verdade, não é evolucionista (Teubner, 1989, p. 99). Portanto, a verdadeira alteração não é a da substituição dos seres, e sim, a do aumento da complexidade. A longo prazo, o direito de hoje é mais complexo que o de ontem e o de ontem mais complexo do que de anteontem (mas, observamos, para sermos completos, que isto é "a longo prazo" porque, a curto prazo, - de novo como na biologia — , a fases de aumento de complexidade, podem suceder fases de simplificação, ainda que estas, pelo menos aparentemente, jamais cheguem ao grau de intensidade de simplificação da fase imediatamente anterior - é a teoria das ondas progressivas - Childe, 1960, p. 287).

A coexistência do Código Civil com o Código de Defesa do Consumidor e a deste com a Lei de Arbitragem impõem, afinal, a seguinte observação: assim como o princípio básico do direito contratual no Código Civil, o da autonomia da vontade, - com seus desdobramentos de liberdade contratual, "pacta sunt servanda" e relatividade dos efeitos contratuais - não foi eliminado pelo Código de Defesa do Consumidor, e sim, acrescentado de outros dois: o princípio do equilíbrio contratual, isto é, equilíbrio dos direitos e obrigações, controlado pela regra da boa-fé objetiva, e o princípio do equilíbrio econômico das partes, implicando proteção ao consumidor ( $v$. art. $4^{\circ}$. do CDC), também, da mesma forma, essa proteção ao consumidor, do Código de Defesa do Consumidor, não foi eliminada pela Lei de Arbitragem. Houve inovação, com aumento de complexidade, sem supressão. A nova Lei, especialmente, nenhuma referência fez à revogação do inciso VII, do art. 51 do Código de Defesa do Consumidor, - continuando, pois, a ser abusiva a cláusula compromissória estabelecida como compulsória em contratos em que uma das partes é consumidor, seja, ou não, de adesão o contrato, conforme será desenvolvido adiante. 
II Algumas considerações sobre a constitucionalidade do compromisso e da cláusula compromissória na Lei de Arbitragem.

A Lei de Arbitragem englobou, sob o nome genérico de "convenção de arbitragem". dois institutos tradicionais: o compromisso e a cláusula compromissória. Enquanto o compromisso é negócio jurídico bilateral, tendo por objeto submeter à decisão arbitral controvérsia já existente, a cláusula compromissória é um pacto de firmar um compromisso futuro, pacto de compromittendo, tendo por objeto submeter controvérsias ainda não concretizadas e, portanto, eventuais, à decisão arbitral.

As diferenças conceituais entre uma e outra figura têm levado alguns juristas a estabelecer conseqüências radicalmente diversas, a ponto de haver quem, diante da nova Lei, considere constitucional - e, portanto, válido - $\mathrm{o}$ compromisso e inconstitucional - e, portanto, inválida -, a cláusula compromissória. Em voto ainda não-publicado, porque, ao que saibamos, o julgamento do caso não terminou, afirmou o Ministro do S.T.F., Sepúlveda Pertence: "Cheguei, porém - depois de longa reflexão à conclusão de que, nesse tópico, a lei foi efetivamente além das marcas impostas pela Constituição ao âmbito de validez da disciplina legal da arbitragem. A constitucionalidade do juízo arbitral perdoese a insistência deriva da renunciabilidade, no caso, do exercício do direito de ação que é o reflexo subjetivo da garantia da prestação jurisdicional, insculpida hoje no art. $5^{\circ}, X X X V$, da Lei Fundamental - relativamente a uma pretensão material disponível. Mas, a renunciabilidade da ação porque direito de caráter instrumental não existe in abstracto, só se pode aferi-la em concreto, pois tem por pressuposto e é coextensiva, em cada caso, da disponibilidade do direito questionado, ou melhor, das pretensões materiais contrapostas, que substantivam a lide confiada pelas partes à decisão arbitral. Segue-se que a manifestação de vontade da qual decorra a instituição do juízo arbitral onde exista a garantia constitucional da universalidade da jurisdição judicial e, pois, do direito de ação não pode anteceder à efetiva atualidade da controvérsia a cujo deslinde pelo Poder Judiciário o acordo implica renunciar. Vale dizer, que não prescinde da concreta determinação de um litígio atual". E mais adiante: "Ora, essa impossibilidade não a pode suprir a lei ordinária, sem ferir a garantia constitucional de que a lei não excluirá da apreciação do Poder Judiciário lesão ou ameaça a direito (CF, art. $5^{\circ}$, XXXV). Só não a transgride o compromisso porque, por força dele, são os próprios 
titulares dos interesses objeto de uma lide já concretizada que, podendo submetê-la a jurisdição estatal, consentem em renunciar à via judicial e optar pela alternativa da arbitragem para solucioná-la. E só para isso. Na cláusula compromissória, entretanto, o objeto dessa opção, posto que consensual, não são lides já determinadas e concretizadas, como se dá no compromisso: serão lides futuras $e$ eventuais, de contornos indefinidos; quanto muito, na expressão de Carnelutti (ob. cit., p. 550), lides determináveis pela referência ao contrato de cuja execução possam vir a surgir. A renúncia, com força de definitiva, que aí se divisasse à via judicial já não se legitimaria por derivação da disponibilidade do objeto do litígio, que pressupõe a sua determinação, mas, ao contrário, consubstanciaria renúncia genérica, de objeto indefinido, à garantia constitucional de acesso à jurisdição, cuja validade os princípios repelem" (Pertence, Ag. reg. em sentença estrangeira n. 5.206-7) (grifos nossos em "lides determináveis" e "objeto indefinido").

O raciocínio desenvolvido, como se percebe, confunde o "determinável" com o "indeterminado" ("indefinido") e supõe que concretizar a vontade das partes seja o mesmo que substituir essa mesma vontade. Em direito, porém, como regra, pouca diferença se faz entre o que é determinado e o que é determinável, eis que, em todo sistema jurídico baseado na lei, há sempre uma margem de indefinição, que deve ser preenchida em cada caso particular; há sempre necessidade de concretização. Também em matéria de negócio jurídico, em especial nos contratos, que constituem um "programa" das partes, para ordenar seu comportamento futuro, existe a mesma indeterminação, - e, muitas vezes, por força da própria natureza jurídica dos institutos, como nas obrigações de dar coisa incerta (arts. 874 a 877 , do C. C. bras.), nas alternativas (arts. 884 a 888 , do C. C. bras.), nos contratos aleatórios (arts. 1.118 a 1.121 , do C. C. bras.) e na própria compra-e-venda simples (arts. 1.123 e 1.124, do C. C. bras.). Não há, pois, como confundir o determinável, que depende somente de concretização, com o indeterminado, que exige acréscimo substancial ex novo.

A verdade é que, considerada inconstitucional a cláusula compromissória, a Lei de Arbitragem não atingirá seus objetivos, eis que sempre foram os obstáculos criados à sua execução específica que impediram o desenvolvimento da arbitragem entre nós. A Lei terá sido inútil.

A distinção entre constitucionalidade do compromisso e inconstitucionalidade da cláusula compromissória, insistamos, não resiste à uma análise minuciosa. Uma cláusula compromissória pode ser muito, ou pouco, 
imprecisa; há graus na imprecisão. Por exemplo, está, entre as primeiras, a que simplesmente estipulasse: "em caso de divergência, as partes farão compromisso arbitral"; está, entre as segundas, a que fixasse o nome do árbitro, as regras do processo de arbitragem e, quanto ao objeto, o limitasse especificamente às questões oriundas de divergência de interpretação contratual. Por outro lado, o próprio compromisso pode ser mais, ou menos, preciso (v. art. 11, da nova Lei); nele, pode, até mesmo, haver problema sobre a nomeação do terceiro árbitro, que é o que mais importa (art. 13, da nova Lei). Do ponto de vista do homem comum, não se percebe por que o juiz não poderia dar sentença que valha como compromisso, quando, da cláusula compromissória, quase tudo conste, e, inversamente, no caso do compromisso, sem fixação do terceiro árbitro, possa ele nomear alguém de sua livre escolha.

$\mathrm{Na}$ verdade, a diferença entre cláusula compromissória e compromisso, tomada para admitir a inconstitucionalidade da primeira e a constitucionalidade do segundo, é, com o devido respeito, raciocínio típico da ultrapassada jurisprudência dos conceitos, a ser substituída in casu pela simples análise tipológica. Diante de cada caso particular, seja compromisso ou cláusula compromissória, o que é preciso fazer é examinar até onde o juiz poderá completar a vontade das partes, isto é, concretizá-la, sem violentar as expectativas de cada contratante.

Resta acrescentar, com o Ministro do S.T.J., Sálvio de Figueredo Teixeira, que a Lei n. 9.307/96 não exclui do Judiciário a arbitragem, seja compromisso ou cláusula compromissória, porque: a. o art. 33 é explícito na admissão de casos de nulidade da sentença arbitral, com exame pelos tribunais; b. a execução coativa somente poderá ocorrer perante o Judiciário; c. a nulidade da sentença pode ser argüida nos embargos à execução, sempre perante o juiz togado; d. a sentença arbitral estrangeira está sujeita à homologação do S.T.F.; e e. é exclusivamente do Judiciário, o exame de qualquer controvérsia que surja sobre direitos indisponíveis (Teixeira, 1997). 
III Compromisso e cláusula compromissória no Código de Defesa do Consumidor, hoje.

Como adiantamos, a Lei de Arbitragem nada alterou no Código de Defesa do Consumidor, sobre os direitos do consumidor. Perante a lei protetiva, o quadro era, e é, pois, o seguinte: o compromisso entre consumidor e fornecedor, desde que sem abuso deste sobre aquele, é permitido; a cláusula compromissória, inversamente, tem presunção absoluta de abusividade e é proibida (art. 51, VII). No compromisso, o abuso é uma possibilidade, a ser examinada caso a caso; na cláusula compromissória é uma certeza, legalmente determinada.

$\mathrm{O}$ art. 51, VII, prescreve como abusivas e, portanto, "nulas de pleno direito", as cláusulas que "determinem a utilização compulsória de arbitragem" A primeira observação a fazer é que o compromisso não está proibido; ele, literalmente, não é cláusula, é ato autônomo; além disso, é realizado quando já há controvérsia existente, de tal forma que, se abuso houver, este terá de ser examinado in concreto; a lei, a priori, não o pressupõe. Uma vez feito o compromisso, e válido porque sem abuso do consumidor, a arbitragem, que se segue, terá por sua vez, que ser decidida sem ferir as normas de ordem pública do Código de Defesa do Consumidor. Portanto, as regras da Lei de Arbitragem, sobre o compromisso - e estamos pensando exatamente nas que dão maior abertura para a decisão, como a possibilidade de decidir por equiidade, — podem se aplicar, mas sempre dentro do limite das normas cogentes do Código de Defesa do Consumidor.

A segunda observação diz respeito à cláusula compromissória; ela está proibida. É verdade que a lei expressamente somente dispõe sobre a que estipula "utilização compulsória de arbitragem", o que parece supor uma permissão de cláusula de arbitragem facultativa. Mas uma cláusula compromissória somente tem sentido prático quando prevê a arbitragem com obrigatoriedade; - o adjetivo, no texto legal, parece ter sido fruto de excesso de preocupação do legislador, para deixar claro que não estava incluindo, na proibição, o compromisso, eis que este, de fato, embora não seja cláusula, pertence ao gênero "convenção de arbitragem" e não é compulsório. Afinal, uma arbitragem facultativa é sempre possível e, por isso mesmo, as partes dificilmente farão previsão desse tipo, em cláusula do próprio contrato; não tem sentido. Portanto, em síntese, a cláusula compromissória, como é 
entendida e estipulada na prática, é nula, se inserida em contrato em que o consumidor é parte.

Por outro lado, para não-consumidores, a Lei de Arbitragem trouxe modificações ao próprio Código de Defesa do Consumidor. O art. 29, desse Código, equiparava não-consumidores a consumidores, em matéria de "práticas comerciais" e de "proteção contratual", verbis: "Para os fins deste Capítulo e do seguinte, equiparam-se aos consumidores todas as pessoas determináveis ou não, expostas às práticas nele previstas" (redação péssima, pouco clara e com erro de concordância, porque, se são dois capítulos, a redação somente poderia ser "expostas às práticas neles previstas"). Tendo em vista essa regra, a cláusula compromissória era também nula em contratos de adesão realizado entre não-consumidores, colocados em posição de desigualdade econômica. Agora, a nulidade deixa de ocorrer na forma ampla anteriormente determinada; será preciso ter em vista a regra específica do $\S$ $2^{\circ}$, do art. $4^{\circ}$, da Lei de Arbitragem. Por essa regra, a cláusula compromissória terá eficácia, nos contratos de adesão, se o aderente tomar a iniciativa de instituir a arbitragem, ou se manifestar sua concordância em documento anexo. A mesma disposição também considera válida a cláusula compromissória, se, redigida em negrito, o aderente puser sua assinatura, ou se puser visto, especialmente para ela (a lei é esta, mas cumpre dizer que isto já se mostrou inútil na Itália, $-2^{\mathbf{a}}$ alínea do art. 1.341 do "Codice civile"-; a verdade é que quem assina, uma vez, "continua na sua" e põe visto, mais uma ou duas vezes, nas mesmas condições).

Alguns autores, antes da Lei de Arbitragem, levantavam dúvidas sobre a nulidade da cláusula compromissória na hipótese de ela ter sido discutida entre partes (cf. Nery Jr., 1991, p. 355). Hoje, para não-consumidores, a solução está expressa no $\S 2^{\circ}$. do art. $4^{\circ}$, mas, repetimos, se um dos contratantes for consumidor, a cláusula compromissória, nesta hipótese, era, e é, nula. A Lei de Arbitragem, embora obedecendo aos "novos tempos" do Estado reduzido, em nenhum ponto alterou a proteção ao consumidor e, bem ou mal, a verdade é que o Código de Defesa do Consumidor "radicalizou" nessa matéria de cláusulas abusivas; de forma excessiva (e até mesmo não-técnica, ao usar a expressão "de pleno direito" — o que, aqui, não vêm ao caso expor), determinou a nulidade, para as cláusulas previstas em seus incisos. $\mathrm{O}$ art. 51 trouxe um rol de hipóteses específicas de cláusulas abusivas, ao lado de uma hipótese genérica de "fechamento" da lista (inciso XV); ora, a previsão das cláusulas abusivas específicas impede que, sobre elas, se façam 
distinções, quer haja, quer não haja, discussão prévia, quer o contrato seja, quer não seja, de adesão.

De lege ferenda, a solução poderia ser outra, eis que, sobre o ponto, variam as legislações. A Diretriz n. 93/13, da União Européia, sobre cláusulas abusivas nos contratos estipulados com o consumidor, inclui, na letra " $\mathrm{q}$ " da lista referida no $\S 3^{\circ}$, do art. $3^{\circ}$, a cláusula compromissória; o texto é: "suprimir ou limitar o exercício de ação judicial ou vias de recurso do consumidor, especialmente, obrigando o consumidor a se utilizar exclusivamente de juízo arbitral não-disciplinado por disposições legais, limitando indevidamente os meios de prova à sua disposição ou impondo ônus de prova que, no sentido da legislação aplicável, incumbiria a outra parte do contrato". De acordo, ainda, com a mesma Diretriz (art. $3^{\circ}, \S 1^{\circ}$ ), uma cláusula contratual deixará de estar no rol exemplificativo dessas cláusulas abusivas, se for objeto de "negociação individualizada". Entretanto, como se sabe, as diretrizes, na União Européia, devem ser incluídas na legislação nacional de cada país; elas fazem, analogicamente, o papel, entre nós, das normas constitucionais não plenamente auto-exeqüíveis. Seguese daí que, por exemplo, na França, onde o Código Civil (art. 2.061) já previa a nulidade da cláusula compromissória, - salvo a hipótese de ser estipulada entre comerciantes -, ela continua a ser nula nos contratos de consumo, independentemente de se tratar, ou não, de contrato de adesão e de ser, ou não, discutida individualmente (Pizzio, 1996, p. 205, com referência, porém, a dois autores, Fouchard e Loquin, que admitem alterações do que está determinado no Código Civil). Na Itália, o caminho seguido foi diferente porque, tendo em vista a referida Diretriz, o próprio Código Civil foi alterado, incluindo-se, nele, em 1996, um "Capo XIV Bis", após o "Capo XIV" do Livro das Obrigações; aí, no art. 1.469 bis, n. 3, há uma lista de cláusulas que se presumem abusivas ("vessatorie"I vexatórias, na terminologia italiana), enquanto que, no art. 1.469 - quinquies, n. 2, há outra lista de cláusulas que são ineficazes, ainda que objeto de tratativas. Todavia, a cláusula compromissória não está nem num nem noutro artigo; está prevista fora desse novo capítulo dedicado ao consumidor; ela está no art. 1.341, sob a rubrica das "condições gerais de contrato"; aí, está proibida, salvo se especificamente aprovada, nos termos que já havíamos adiantado acima (v. Alpa/ludica, 1996). De lege lata, portanto, a situação francesa é a mesma nossa, para o consumidor, e a italiana, é a mesma nossa, para o não-consumidor. 
Resumindo: o compromisso é sempre permitido e a cláusula compromissória continua proibida nas relações em que o consumidor é parte, por força do inciso VII, do art. 51 do Código de Defesa do Consumidor, não-revogado; nas relações entre não-consumidores, tratando-se de contratos de adesão, há de se aplicar o $\S 2^{\circ}$, do art. $4^{\circ}$, da Lei de Arbitragem. Legem habemus.

São Paulo, 28 de julho de 1997.

\section{BIBLIOGRAFIA}

ALPA, IUDICA et alii. Codice civile con commento essenziale di giurisprudenza. s.l.p., Kluwer Ipsoa, 1996.

CHILDE, V. Gordon. O que aconteceu na História, tradução de Waltensir Dutra. Rio de Janeiro : Zahar Editores, 1960.

DWORKIN, Ronald. Talking Rights Serriously. Londres : Duckworth, 1991.

GALGANO, Francesco. Il diritto privato fra codice e Costituzione. Bolonha : Zanichelli, 1980.

LIPARI, Nicolò. "Sistematica giuridica e nuovo contrattualismo". in Rivista di Diritto Civile, n. 32, 1986.

NERY JR., Nelson. In Código Brasileiro de Defesa do Consumidor Comentado pelos Autores do Anteprojeto. Rio de Janeiro : Forense Universitária, 1991.

PIZZIO, J. P. Code de la consommation commenté. $2^{\mathrm{a}}$ ed. Paris : Montchrestien, 1996.

TEIXEIRA, Salvio de Figueiredo. A Arbitragem no Sistema Jurídico Brasileiro" in Lex-Jurisprudência do Superior Tribunal de Justiça, n. 94, São Paulo, Lex, junho de 1.997.

TEUBNER, Gunther. O Direito como Sistema Autopoiético, tradução de José Engrácia Antunes. Lisboa : Fundação Calouste Gulbenkian, 1993. 